During the first week in January of this year a 6-year-old girl attended the ophthalmic outpatient department for assessment of a squint. During the course of the visit a drop of $1 \%$ cyclopentolate was instilled into each conjunctival sac in order to dilate the pupil and paralyse the ciliary body. Fifteen minutes later a drop of $0.25 \%$ hyoscine was instilled as the pupil was not dilating. This produced sufficient mydriasis to allow refraction to be performed and the appropriate spectacles were ordered. She was allowed home to be followed up in the orthoptic department.

On the way home the mother noticed that the child tripped twice. About half an hour later she continued to trip over but in addition became very aggressive, saying odd things. She also tried to pick up non-existent objects. She was brought to the accident department where she was found to be markedly ataxic, with hallucinations; she tried picking up non-existent mice and scratched herself because she said spiders were crawling over her body. Her pulse rate was 70 beats per minute and her blood pressure was $100 / 60 \mathrm{~mm} \mathrm{Hg}$. She was admitted to the paediatric ward and sedated with diazepam. The following morning she was much more rational and by lunch-time she was well oriented and coherent. She could not recall any of her past experience from leaving the outpatient department the previous morning.

In order for refraction to be carried out accurately in children it is usually essential to relax the tone of the ciliary muscle. The most effective drug to produce relaxation of accommodation is atropine instilled into the eye as drops or as ointment. Unfortunately, the cycloplegic effects of atropine can last for two weeks. Shorter-acting cycloplegic drugs are hyoscine and cyclopentolate. Hallucinations are a rare complication of atropine and perhaps it is the similar part of the hyoscine and cyclopentalate molecules which produced this effect in our patient. The remarkable feature, however, is that a sufficient amount of drugs could be absorbed from a few drops of dilute solution to produce such dramatic effects. -We are, etc.,

Ophthalmic Department, St. Albans City Hos
St. Albans, Herts

\section{Closing Volume and Pregnancy}

SIR, - We have read with interest the paper by Dr. D. R. Bevan and others (5 January, p. 13). The authors conclude that "the apparent increase in closing volume (CV) merely represents a fall in functional residual capacity (FRC)-airway closure occurring at the same lung volume." We believe that this calls for some comment in the light of their results.

It is known that $\mathrm{CV}$ in normal subjects increases with age ${ }^{2}$ and it is also generally expressed as a percentage of vital capacity (VC) or total lung capacity (TLC) to make allowance for variation in body size. As the authors state that the reduction in VC in their pregnant subjects was small, we have converted the values obtained in the sitting posture to $\mathrm{CV} / \mathrm{VC} \%$ and compared them with the results of Buist and Ross ${ }^{2}$ obtained by the same method in 152 seated female non-smokers. Six of the 20 pregnant subjects (nos. 1, 3, 6, 16, 18, and 19) have CV/VC\% (sitting) more than 2 S.D. above the mean predicted value for their age (the value being exceptionally high in nos. 1 and 3 ), and five of these are among the 10 subjects in whom CV exceeded FRC in the sitting posture. This may be evidence of a real increase in CV in these subjects; such an increase could possibly be related to smoking, ${ }^{1}$ but this cannot be decided without knowledge the subjects' smoking habits.

The authors have related $\mathrm{CV}$ to absolute lung volume by assuming that residual volume (RV) forms $20 \%$ of TLC. This assumption may have been unnecessary and could be misleading, for Buist and Ross ${ }^{2}$ have estimated $R V$ from the dilution of the single breath of oxygen used to measure CV itself. It should therefore be possible to relate the lung volume at the onset of airway closure to estimates of TLC or FRC derived from VC, expiratory reserve volume (ERV), and the original records of the expired nitrogen concentration.

An unusual finding is that $\mathrm{CV}$ fell significantly when pregnant subjects moved from sitting to supine posture. This is in contrast to findings in normal subjects ${ }^{13}$ and to our findings in obesity. ${ }^{4}$ Though the authors claim that the conditions for which their patients were admitted were unlikely to have an effect on $\mathrm{CV}$, we note that if the subjects are divided into groups of eight with hypertension and 12 without, the mean fall in CV is more marked in the hypertensive group $(336 \pm$ S.E.M. $112 \mathrm{ml})$ than in the others $(116 \pm$ S.E.M. $51 \mathrm{ml})$, though the difference between the groups just fails to reach statistical significance $(0.1>P>0.05)$. Comparison of hypertensive and normal pregnant subjects with allowance for smoking habits might reveal a true difference in CV.

In obesity the hypoxaemia which occurs in some subjects sitting and becomes worse on lying down can be related quantitatively to the decline in ERV with increasing weight and to the amount by which $\mathrm{CV}$ exceeds FRC. ${ }^{4}$ Ang et al..$^{5}$ found that arterial $\mathrm{Po}_{2}$ fell on recumbency in late pregnancy, and this suggested that a similar mechanism might have been operating in these circumstances. The finding by Bevan et al. that CV exceeded FRC in only six subjects supine compared with nine sitting still leaves uncertain the cause of this increase in hypoxaemia. We believe the relationships between $\mathrm{CV}$, ERV, posture, and arterial $\mathrm{Po}_{2}$ in pregnancy may require further investigation, especially in normal pregnancy in smokers and nonsmokers.-We are, etc.,

University Hospitals,

M. J. B. FAREBROTHER

Newcastle upon Tyne

G. J. R. MCHARDY

University Department of Respiratory Diseases, City Hospital,

1 MoCarthy, D. S., Spencer, R., Greene, R., and Milic-Emili, J., American fournal of Medicine,
1972, 52, 747. 2 Buist, A. S., and Ross, B. B., American Review
of Respiratory Disease, 1973, 107, 744 .

3 Collins, J. V., Clark, T. J. H.. McHardy-Young, S., Cochrane, G. M., and Crawley J., British Fournal of Diseases of the Chest, 1973, 63, 19. Munro, J. F., Bulletin de Pathophysiologie Respiratoire, 1973, 9, 1264.

Ang, C. K., Tan, T. H., Walters, W. A. W. and Wod, C., British Medical fournal, 1969,

\section{Levodopa and Chronic Bronchitis}

SIR,-The following finding may be of interest. I cannot find a similar recorded case.

The patient, a man aged 56 years suffering from chronic bronchitistwith severe bronchospasm for over 18 years, has tried many types of bronchodilator. He has taken Amesec capsules (containing amino- phylline, ephedrine, and amylobarbitone) for the past eight years, along with courses of antibiotics, but had become so dyspnoeic that in 1970 a regional medical officer of the Department of Health and Social Security described him as a "respirator y cripple." In September 1973 he developed Parkinson's disease and I started treatment with levodopa. In February 1974 he told me that during the whole period since taking levodopa he had taken the whole period since taking levodopa he had taken only two Amesec capsules, whereas previously he
required up to three daily. He had no dyspnoea required up to three daily. He had
and his Parkinsonism had improved.

I discussed this patient with Professor C. D. Marsden of King's College Hospital, London, who suggested that this response might be explained by the conversion of dopa into a metabolite that dilates the bronchioles. I would be interested to know whether this beneficial effect of levodopa on chronic bronchitis with severe bronchospasm has been previously observed.-I am, etc.,

London S.E.13

HARRY G. JEFFS

\section{General-practitioner Deputizing Services}

SIR,-I read with interest the article on G.P. deputizing services (Supplement, 16 February, p. 9) and feel I must point out their shortcomings from the patients' view.

These services are largely staffed by junior hospital doctors working in a specialty, and they do not have the broad base of knowledge that the G.P. should have. The tendency is to send to hospital cases outside their expcrience which in many cases can be treated at home. The deputy is paid according to the number of calls, so that there is no encouragement to practice good medicine; the call often consists of a few quick questions, a prescription, and off to the next call. If the patient is not diagnosed at the first call there is no encouragement to observe the patient in his home for a few hours; he is often sent to hospital without need.

I have worked in a junior hospital grade for three years in a region where deputizing services are used and I am frankly appalled by the standard of care which the patient received from these services.-I am, etc.,

KEITH WELIS

Bramhall, Cheshire

SIR,-In reply to the article by Dr. B. T. Williams and Professor J. Knowelden (Supplement, 16 February, p. 9), I think it necssary to comment on some of the conclusions drawn in an otherwise excellent report.

In looking at the "popularity" of deputizing services among general practitioners the authors have measured the percentage of users against the total number of general practitioners in the appropriate executive council areas. It would have been much more appropriate to measure the percentage of users in the geographical areas actually covered by deputizing services. Most services overlap into the county areas to some extent and the county executive councils therefore technically have deputizing services in their areas. The majority of the county area, however, might well have no service offered at all. The number of general practitioners for whom a service is available is shown in the report as 14,561. The true figure is probably much nearer 10,000 and the percentage of users is therefore probably much higher than that shown.

The authors highlight the lack of con- 